http://jmscr.igmpublication.org/home/

ISSN (e)-2347-176x ISSN (p) 2455-0450

crossref DOI: https://dx.doi.org/10.18535/jmscr/v7i8.39

Journal Of Medical Science And Clinical Research

\title{
Extensive Pityriasis Alba: Case Report with Review of Literature
}

\author{
Authors \\ Saru Thakur ${ }^{1}$, Reena K Sharma ${ }^{2}$, GR Tegta $^{3}$, Mudita Gupta ${ }^{4}$ \\ ${ }^{1}$ Post graduate student, ${ }^{2}$ Senior Resident, ${ }^{3}$ Professor and Head, ${ }^{4}$ Assistant Professor, Deptt. of Dermatology, \\ Venereology and Leprosy, Indira Gandhi Medical College, Shimla, Himachal Pradesh \\ *Corresponding Author \\ Mudita Gupta \\ Deptt. of Dermatology, Leprosy and Venereology, Indira Gandhi Medical College, Shimla,
} Himachal Pradesh, India

\begin{abstract}
Pityriasis alba (PA) is a common disorder seen in children, marked by the presence of hypo pigmented macules usually over the face. It is a self-limiting condition with no reliable treatment. It is observed more often in individuals with darker complexions but occurs equally in individuals of all skin colors. There are two rare variants of PA, one of which is extensive PA. We are reporting a case of extensive PA in a 9-yearold boy due to rarity of its occurrence.

Keywords: pityriasis alba, extensive, hypo pigmented, self-limiting.
\end{abstract}

\section{Introduction}

Pityriasis Alba (PA) is a common benign condition usually seen in children 3 to 16 years of age. It is characterized by the presence of hypo pigmented slightly scaly macules frequently limited to the face typically, but other sites such as neck, arms and shoulders may also be involved. Atypical forms of PA are also known, which include extensive and pigmenting types. Extensive PA refers to the presence of typical PA lesions distributed in a generalized fashion and not limited to the face ${ }^{(1)}$. PA is a very common entity but generalized lesions in extensive PA have been reported uncommonly. Adults are usually affected with extensive forms. However, we are reporting a case of extensive PA in a 9-year-child so as to encourage interest in this entity, which has not been reported since many years.

\section{Case Report}

A 9 years boy was brought to the dermatology department for presence of multiple whitish lesions all over the body. The mother had started noticing these hypo pigmented patches over the trunk since past 2 years. However, as these were asymptomatic with no preceding erythema or inflammation, she did not pay much attention. These lesions kept on increasing in number gradually and spread to involve the extremities and the face. The lesions accentuated after exposure to sun. On physical examination, there were multiple ill defined, symmetrically distributed hypo pigmented macules and patches over the face, trunk and extremities varying in size from $0.2 * 0.5 \mathrm{~cm}$ to $1 * 2 \mathrm{~cm}$ with ill defined margins and mild scaling over surface at places. (Figure 1) There was no fluorescence on wood's 
lamp examination and potassium hydroxide $(\mathrm{KOH})$ mount was negative from the lesions. All the routine investigations were within normal limits but there was hyperkeratosis, acanthosis and lymphohistiocytic infiltrate in perivascular areas on histopathological examination.

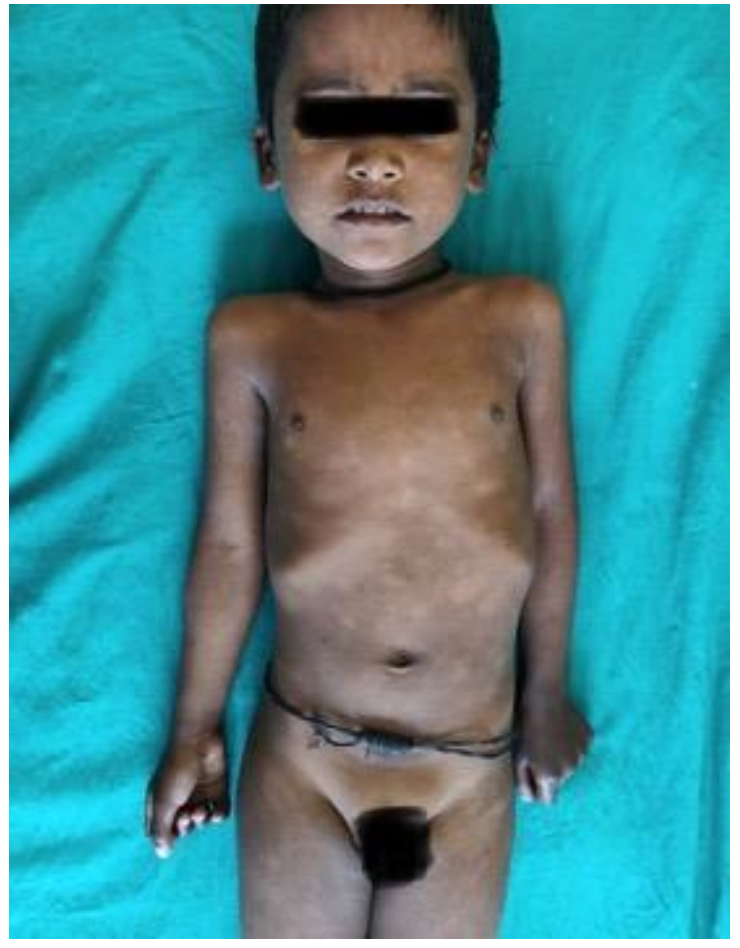

Figure 1: Multiple hypopigmented macules and patches over face, trunk and extremities.

\section{Discussion}

PA is a commonly observed entity affecting about $1.9 \%$ to $5.25 \%$ of preadolescent children ${ }^{(2)}$ and has a worldwide distribution. PA does not have any gender pre disposition ${ }^{(3,4)}$ though male preponderance has been reported by some ${ }^{(1)}$ as seen in our case. PA is also known by names such as erythema streptogenes, pityriasis streptogenes, and impetigo furfuracea ${ }^{(2)}$.

The exact etiopathogenesis is not known for PA. However, xerosis, atopy, sun exposure, wind and soap have been considered as etiological factors leading to dermatitis. Copper deficiency has also been implicated. There was increased incidence of infections among the affected patients but no definitive associations have been found. It has been widely accepted as a manifestation of atopic dermatitis $^{(2)}$.

Clinically, PA manifests as hypopigmented patches with slight scaling over surface. The lesion starts as an irregular, circular or oval, pink patch, with an elevated, slightly erythematous border occasionally. Erythema fades in a few weeks leaving a hypo pigmented macule covered by fine scales. The hypo pigmentation persists for months to years and fades eventually. PA has been considered as a form of dermatitis that results in the reduction of melanocytes and melanosomes without any detectable defect in melanin transfer ${ }^{(3)}$.

There are two rare variants of PA, pigmenting and extensive. Pigmenting pityriasis alba is characterized by presence of hyper pigmented bluish scaly patches surrounded by hypo pigmented halo affecting mostly the face $^{(3)}$. Extensive PA on the other and, has a widespread distribution, characterized by features of PA without any preceding erythema. Extensive PA is seen more commonly in adults and usually involves the lower half of the trunk symmetrically. The lesions resemble classical PA usually.

The reduction in pigmentation has been attributed to the decreased number of active melanocytes and decrease in the number and size of melanosomes in the affected skin. The histology resembles classical PA and is nonspecific. Along with the above findings, perivascular mononuclear infiltrates, variable hyperkeratosis, parakeratosis, intercellular edema and intracytoplasmic lipid droplets may be seen ${ }^{(5)}$.

PA needs to be differentiated from other hypo pigmented lesions as seen in post-inflammatory hypomelanosis such as after the clearing of papulosquamous lesions, secondary syphilis, drug eruptions, pityriasis versicolor etc. Absence of a preceding rash can help in distinguishing these. Nevus depigmentosus is a hypo pigmented macule with well-defined borders and normal histology. Vitiligo is a depigmented patch with loss of melanocytes. Diascopy can differentiate nevus anemicus. Ash leaf macules are usually present at birth with other stigmas of tuberous sclerosis ${ }^{(2)}$. Photoprotection, use of emollients and lubricants 
remain the mainstay of the therapy. The benign and self-limiting nature of the entity needs to be assured so as to reduce anxiety among patients and attendants. A wait and watch policy can be adopted as was done in our case. Mild steroids may be required for inflammatory lesions. No therapy is completely successful though topical steroids, tretinoin $^{(2)}$, oral methoxsalen photochemotherapy ${ }^{(6)}$ has been tried with some success.

\section{Conclusion}

Extensive Pityriasis Alba is an atypical variant of pityriasisalba. The benign and self-limiting nature of the disorder must be assured so as to reduce the anxiety related to the unsightly appearance.

\section{Declaration of Patient Consent}

The authors certify that they have obtained all appropriate patient consent forms, in which, the patient's attendant has given his consent for his child's images and other clinical information to be reported in the journal. The attendant understands that name and initials will not be published and due efforts will be made to conceal identity, but anonymity cannot be guaranteed.

\section{Conflict of Interest: Nil}

\section{Sources of Support \& Sponsorship: Nil}

\section{References}

1. Lee D, Kang JH, Kim SH, Seo JK, Sung HS, Hwang SW.A Case of Extensive Pityriasis Alba. Ann Dermatol 2008; 20(3): 146-8.

2. Lin RL, Janniger CK. Pityriasisalba.Cutis 2005;76:21-24.

3. AlShahwan MA. Pigmenting pityriasis alba: Case report and review of the literature. Journal of the Saudi Society of Dermatology \& Dermatologic Surgery 2012;16 :31-33. doi:10.1016/j.jssdds.2011.11.002.

4. Sandhu K, Handa S, Kanwar AJ. Extensive pityriasis alba in a child with atopic dermatitis. PediatrDermatol 2004;21:275-276.

5. Zaynoun ST, Aftimos BG, Tenekjian KK, et al. Extensive pityriasis alba: a histological histochemical and ultrastructural study. $\mathrm{Br} \quad \mathrm{J}$ Dermatol 1983;108:83-90.

6. Zaynoun S, Jaber LA, Kurban AK. Oral methoxsalen photochemotherapy of extensive pityriasisalba. Preliminary report. J Am AcadDermatol 1986;15: 6165. 